University of Nebraska - Lincoln

DigitalCommons@University of Nebraska - Lincoln

Faculty Publications, Department of Psychology

Psychology, Department of

2009

What's Fair in Foul Weather and Fair? Distributive Justice across

Different Allocation Contexts and Goods

John T. Scott

University of California - Davis

Brian H. Bornstein

University of Nebraska-Lincoln, bbornstein2@unl.edu

Follow this and additional works at: https://digitalcommons.unl.edu/psychfacpub

Part of the Psychiatry and Psychology Commons

Scott, John T. and Bornstein, Brian H., "What's Fair in Foul Weather and Fair? Distributive Justice across Different Allocation Contexts and Goods" (2009). Faculty Publications, Department of Psychology. 395. https://digitalcommons.unl.edu/psychfacpub/395

This Article is brought to you for free and open access by the Psychology, Department of at DigitalCommons@University of Nebraska - Lincoln. It has been accepted for inclusion in Faculty Publications, Department of Psychology by an authorized administrator of DigitalCommons@University of Nebraska - Lincoln. 


\title{
What's Fair in Foul Weather and Fair? Distributive Justice across Different Allocation Contexts and Goods
}

\author{
John T. Scott University of California, Davis \\ Brian H. Bornstein University of Nebraska, Lincoln
}

\begin{abstract}
The Gulf coast hurricanes of a few years ago vividly highlighted important questions concerning the fair distribution of resources that are of continual concern in the more mundane distributive policies of the modern state. We present an experimental study of allocation decisions across two allocation contexts-nonemergency and emergency (flood) conditions - and with regard to qualitatively different goods-money, prescription medicine, and food. Distributive behavior is likely to vary across context and good depending on how individuals weigh distinct and competing allocation principles-merit, need, and equality here-in different circumstances. We find that allocation behavior is complex but structured, with context and good having predictable effects on the allocation strategies individuals employ. Although we find that individuals overall tend to weigh certain allocation principles more heavily in certain contexts and with regard to certain goods (e.g., emphasizing need in an emergency context or with regard to prescription medicine), we also find that they do not behave in a lockstep fashion and that they still employ a variety of allocation strategies, even in nonobvious ways, in every condition. Our study makes both a theoretical and an empirical contribution to our understanding of allocation behavior and distributive justice with implications for understanding the distributive decisions of policy makers as well as citizens' views of the fairness and legitimacy of policies.
\end{abstract}

T he immediate and lingering effects of the hurricanes Katrina and Rita, which hit the Gulf Coast in 2005, as well as more recent natural disasters such as flooding in the Midwest, vividly highlight several important issues concerning distributive justice. In addition to the questions about systematic inequities revealed by the disproportionate effects of the Gulf Coast hurricanes in particular, these natural disasters spurred debate about the appropriate distribution of resources to those affected. For example, in response to the crisis the Federal Emergency Management Administration (FEMA) and the Red Cross distributed debit cards to those affected by Katrina to purchase food, clothing, housing, and other immediate necessities, but this policy was promptly halted after stories - apocryphal or not - that the cards were being used by recipients for nonessential items like designer boots and bar tabs. Wouldn't it be more fitting, critics asked, to provide essential goods directly and to allocate them with regard to the specific deservingness or need of individuals? While abandoning this novel debit card program, governmental and nongovernmental agencies nonetheless had to develop criteria for the appropriate distribution of a variety of different goods from money and food to medical care and housing. ${ }^{1}$

Natural cataclysms are rare events, but they dramatically highlight issues of allocation context and type of good that are of continual concern in the more mundane distributive policies of the modern state, as well as decisions by nonstate organizations and even ordinary individuals. While money is perhaps the good most widely distributed-and collected-by government, many of the most important public policies involve the distribution of nonmonetary resources. For example, healthcare resources are allocated through programs like Medicare,

\footnotetext{
${ }^{1}$ For reports on the debit card policy, see FEMA press release HQ-05-218 (September 7, 2005); "Storm and Crisis: Government Assistance," New York Times, September 9, 2005 (A17).
}

The Journal of Politics, Vol. 71, No. 3, July 2009, Pp. 831-846

doi:10.1017/S0022381609090744

(C) 2009 Southern Political Science Association

ISSN 0022-3816 
Medicaid, and organ transplant registries. Welfare benefits include food and food stamps, and these goods may be rationed more widely in certain circumstances, such as wartime or drought. The fact that these various goods are allocated through a plethora of government programs, each with its own distribution rules, suggests that different norms apply in distributing different goods. Moreover, the fact that the rules governing the distribution of these goods are often altered in the face of changing contexts, such as poor economic conditions and natural disasters, further suggests that the use of these distributive norms is influenced by context. In short, allocation context and type of good appear to be important factors in determining who gets what, when, and how.

The complex questions of the just allocation of goods at issue in emergencies and normal times alike are amenable to systematic study through experimental analysis of the structure of distributive justice behavior. In this paper, we contribute to this research with an experimental study of individuals' use of distributive justice norms in making allocation decisions across different allocation contexts and with regard to qualitatively different goods. We examine the distribution of a variety of several goods central to social welfare policies-money, prescription medicine, and food-and we examine their distribution in two allocation contexts: a nonemergency condition and an emergency (flood) condition. By systematically varying the allocation context and goods, we analyze how these attributes of the allocation decision, as well as individual-level characteristics, influence distributive behavior. We examine these allocation decisions under a condition of strict impartiality in order to study distributive justice behavior apart from instrumental factors, and even apart from such ultimately self-centered motives as reciprocity or "inequity aversion" (Fehr and Schmidt 1999; see Frohlich, Oppenheimer, and Kurki 2004). As Konow (2001, 139) argues, we need to isolate "unbiased justice" to understand the interactions among principled and egocentric factors that determine behavior.

Our study of the effects of context and good on allocation decisions makes both a theoretical and an empirical contribution to a growing literature on allocation behavior and distributive justice. Experimental and other empirical studies across several disciplines have shown that individuals have "pluralistic" views on justice that draw on several distinct allocation principles and that they employ and weigh these principles in accordance with predictable factors (see Deutsch 1986; Hegtvedt and Cook 1999; Konow 2003; Leventhal, Karuza, and Fry 1980;
Mikula 1980; Miller 1999, chap. 4; Schwinger 1980; Törnblom 1992; Tyler et al. 1997). As one recent study summarizes these findings, distributive justice behavior is "complex but structured" (Michelbach et al. 2003). Despite this pluralistic approach and its findings, however, prior research has been surprisingly limited both theoretically and empirically with regard to its very pluralism. First, although this empirical research into distributive justice often draws on normative theories such as Walzer's (1984) argument that different allocation norms are appropriately applied in different "spheres of justice," the central arguments of this influential vein of contemporary normative theory concerning the importance of allocation context and type of good have received relatively little empirical study. Our study is directly inspired by pluralist normative theories and examines their central claims. Second, existing empirical studies have focused largely on the allocation of a single good-namely, money or income-and with regard to a single contextnamely, productive activities (see esp. Frohlich and Oppenheimer 1992; Michelbach et al. 2003; Mitchell et al. 1993; Scott et al. 2001). One advantage of the most sophisticated studies of the distribution of money and income, however, has been to pose participants with tradeoffs among different allocation strategies that emphasize different allocation principles, thereby enabling us to more systematically understand the structure of allocation decisions. We apply this approach to the study of the effect of context and good on allocation behavior, where previous studies have generally been less systematic. Our experimental design is based on the normative and empirical scholarship regarding distributive justice and allocation behavior, and so we outline these literatures before presenting our experimental design and predictions and then our results.

Our results reveal that both allocation context and type of good have strong and predictable effects on allocation behavior. Overall, we find that participants tend to weigh merit more heavily in the nonemergency context and to be more oriented toward need in the emergency (flood) context, and we find that across both contexts participants tend to emphasize merit when allocating money, emphasize need when allocating prescription medicine, and employ a more mixed set of strategies-including an egalitarian strategy-when allocating food. However, while we find more emphasis on certain allocation principles in different contexts and with regard to different goods, we also find that participants do not behave in a lockstep fashion and that they still employ a variety of allocation strategies in 
complex, and sometimes nonobvious, ways in every condition.

Our study makes both a theoretical and an empirical contribution to our understanding of allocation behavior and distributive justice with implications for understanding the policies of the modern distributive state. Participants in our study perform a task that, although admittedly stylized, makes their role analogous to that of a policy maker or bureaucrat determining what allocation policies to employ in different domains. Their behavior therefore gives us insight into the decision making of politicians and policy makers who must also continually balance competing allocation strategies in ways that are sensitive to differing contexts and qualitatively different goods. Furthermore, our participants' behavior also sheds light on how ordinary citizens balance the core values (see Feldman 1988) that determine their views of the fairness and legitimacy of the social policies of the modern state.

\section{Which Is the Fairest One of All?}

Philosophers, politicians, and parents have long sought a clean way to cut the Gordian knot of distributive justice, from Socrates' "minding one's own business" to Rawls' "justice as fairness," to the simple expedient used by parents from time immemorial of dividing a piece of cake by the method of one child cuts and the other chooses (see Brams and Taylor 1996). Little reflection is necessary, however, to realize that fairness is no simple matter. Potentially relevant differences in context, goods, and recipients soon suggest themselves, rendering allocation a complex problem.

\section{Pluralist Theories of Distributive Justice}

The complexity of distributive justice is reflected in an influential family of contemporary normative theories that share a "pluralist" approach. Pluralist theories developed largely in reaction to other distributive theories that reduce allocation to a single dimension, as in utilitarianism or equity theory, or that argue for a prioritization of principles, as in Rawls. Pluralists suggest that such theories do injustice to our intuitions about distributive justice, either forcing the distribution of goods into the procrustean bed of a single allocation principle to the exclusion of other plausibly relevant principles or being unable to give guidance in domains or situations where the demands of justice seem to require it. In the emergency context of a natural disaster with which we have illustrated the problem of distribution of goods, for example, maximizing one allocation principle to the exclusion of others, such as maximizing efficiency according to the dictates of utilitarianism, almost certainly conflicts with our commonsense intuitions about justice. Likewise, Rawls' (1971) theory of justice as fairness does not seem to speak to such an emergency allocation context at all, or even offer much guidance about how different "primary goods," which Rawls treats as equivalent, might be legitimately distributed according to different principles or other criteria.

Perhaps the most prominent pluralist theory is Walzer's (1983) "spheres of justice." Arguing that the "search for unity" in distributive justice theory "is to misunderstand the subject matter of distributive justice" $(1983,4)$, Walzer suggests instead that there are different "spheres" of society in which different distributive norms should predominate in allocating the various goods typically associated with these spheres. For example, he argues that in the sphere of security and welfare the allocation of medical care "should be proportional to illness [i.e., need] and not to wealth" $(1983,86)$, whereas other principles, such as desert, become paramount in other situations, notably in productive activities in the sphere of money and commodities. Similarly, in his "local justice" approach, Elster $(1992,1993)$ contends that the allocation of scarce resources should follow different principles in different arenas, for example stating: "Need is central in allocating organs for transplantation, merit in admitting students to college, and seniority in selecting workers for layoffs" (Elster 1993, 259). Finally, Miller (1999) develops a similar approach in his explicitly pluralist theory, arguing that the principles of social justice (need, merit, and equality) depend upon context, and in particular the "mode of human relationships" at issue. In sum, according to this broad theoretical approach, justice is context dependent but not context specific, meaning that the principles used in allocation do not vary simply according to context but rather are appropriately given varying weights in different contexts (see also Deutsch 1986; Konow 2003, 1231-32).

\section{Empirical Studies of Distributive Behavior}

In order to buttress their claims, pluralistic theories often appeal to empirical studies of allocation behavior and opinions (see esp. Miller 1999, chap. 3). The empirical study of distributive behavior and opinions 
has been conducted for well over four decades in several fields, primarily psychology and political science, and using several methods, including public opinion surveys and especially experiments (for overviews see Lerner and Lerner 1981; Mikula 1980; Miller 1999; Törnblom 1992; Tyler et al. 1997). Overall, this research has shown that distributive justice decisions are complex but structured, with individuals using a finite group of allocation principles-e.g., equality, need, merit, and efficiency-in making decisions or judgments and weighing these principles according to predictable factors, including individuallevel attributes (see Konow 2003; Scott et al. 2001).

Despite the influence of pluralist theories on experimental and other studies of distribution, this research has been somewhat limited both theoretically and empirically with regard to its very pluralism. First, despite their appeal to the central arguments of pluralist theories regarding the importance of allocation context and type of good, differences in context and good have not received much systematic empirical analysis. Second, existing empirical studies have tended to focus on the allocation of money or income and with regard to productive activities alone. This focus on money and income has had its advantages, for it has allowed scholars to focus on the structure of allocation behavior-i.e., the relationships among the allocation principles themselves and what factors influence how individuals weigh them-with regard to a single, important, and relatively concrete good. The study of the effects of allocation context and type of good, in turn, has tended to be less systematic in this regard. Our aim in the present study is not only to draw more broadly on pluralistic theories of justice in order to extend our understanding of distributive behavior, but also to extend the strengths of the existing studies focusing on the allocation of money into the study of the effect of different contexts and goods.

Perhaps the most theoretically compelling aspect of the most sophisticated empirical studies focusing on the distribution of money and income has been their systematic manipulation of allocation principles in order to pose participants with clear tradeoffs among these principles and thus clearly reveal the structure of allocation behavior. For example, in a microlevel study involving groups choosing a scheme for fairly allocating income derived from a hypothetical or actual productive task, Frohlich and Oppenheimer (1992) found that the clear majority of groups chose a compromise between need (setting a minimum floor for income) and efficiency (i.e., maximizing total income). Several macrolevel studies examining individuals' views about the distribution of income across society confirm that distributive justice decisions generally involve tradeoffs among distinct principles. Scott et al. (2001) identified several distinct allocation strategies that balanced equality, efficiency, and need contingent upon assumptions about merit (see also Michelbach et al. 2003; Mitchell et al. 1993; Mitchell et al. 2003). Despite their limited focus in terms of context and good, then, the ultimate concern of these studies with the allocation principles themselves provides good theoretical warrant to expect that distributive justice behavior concerning different allocation contexts and goods will have a similarly complex yet structured character.

The study of the effects of context and type of good on allocation behavior is both theoretically and empirically less developed. With regard to different types of goods, the few existing studies confirm the intuition that individuals will tend to emphasize different principles when distributing qualitatively different goods. Nonetheless, at least two characteristics of this research make it difficult to compare across these studies or to draw more systematic conclusions about the structure of allocation behavior. First, the sheer variety and generally atheoretic choice of "goods" examined in these studies make it difficult to generalize their results for further systematic examination. Second, these studies commonly examine both "goods" that are "goods" independent of the relationship between giver and recipient (e.g., money) and "goods" that are only such because of the nature of the relationship (e.g., love), with the result that it is difficult to study the structure of the allocation behavior independent of other factors than the difference in the goods themselves. These researchers are not unaware of these difficulties. Foa and Foa (1974, chap. 5; see also Törnblom and Foa 1983), for example, argued that variation in the use of allocation principles across the goods they examine (love, service, status, tangible goods, information, and money) can be explained in part by their different exchange properties. They accounted for many of the differences they find in the interpersonal exchange of the goods they examine by classifying resources along two dimensions: particularism (i.e., the value of a resource as influenced by the particular persons involved in exchanging it and their relationship to one another) and concreteness (i.e., whether the resources are relatively concrete as opposed to symbolic). Some of the findings of these studies are relevant to our research, for example that individuals evaluating hypothetical transfers tended to prefer 
equality when distributing tangible goods (as well as love and services) and to split in their preferences over equality and merit when allocating money (Törnblom and Foa 1983; see also Herlocker et al. 1997).

In order to obviate the complexities associated with the confounding effects of the nature of the interpersonal relationship and the character of the goods, in our study we will examine only how disinterested third-party allocators distribute concrete goods. More similar to our study in these regards, and therefore more relevant, is a study by Skitka and Tetlock (1992) which assessed justice preferences of third-party allocators for the distribution of three different goods: organs available for transplantation, the drug AZT for AIDS patients, and low-income housing for the poor. They found that ratings of various distribution options were highly correlated across resource, perhaps because the three goods they examined are all highly associated with need. In our study, we build on this approach and broaden it to look at a number of concrete goods that are not all highly associated with a single allocation principle. Finally, in a nonexperimental study especially relevant to our analysis of fairness in a flood, Skitka (1999) examined public opinion in the wake of the 1993 flood in the Midwestern United States, analyzing the determinants of willingness to extend humanitarian aid to victims of the disaster. She found that respondents were more supportive of providing for flood victims' "primary" needs (e.g., food items like milk) as opposed to "secondary" needs (e.g., cookie dough). Furthermore, she found that respondents-even in the context of a natural disasterconsidered information about personal responsibility (e.g., whether recipients had flood insurance) when judging deservingness, with liberals more likely to support providing assistance regardless of perceived responsibility in comparison to conservatives. In our study we similarly examine how individuals weigh need and merit in their allocation decisions in both an emergency context, similar to Skitka, and a nonemergency context.

While there is therefore little research into how different types of goods are distributed, greater consideration has been paid to the influence of situational factors on allocation behavior, or what usually falls under the broad rubric of "context." Once again, the variety of contexts that have been examined is quite broad. Commonly cited context variables include the relationship between parties (Bierhoff, Buck, and Klein 1986; Foa and Foa 1974; Mikula 1980); whether the parties expect future interactions (Bierhoff et al. 1986); allocation objectives, such as creating solidarity versus maximizing efficiency (Deutsch 1986; Mikula 1980); environment or institutional setting (Foa and Foa 1974); and disclosure of the allocation decision (Mikula 1980). Several of these findings are potentially relevant for our study of allocation behavior in an emergency (flood) versus nonemergency (nonflood) context. For example, Bierhoff, Buck, and Klein (1986; see also Deutsch 1986) proposed that different principles will be preferred in different domains: equality is preferable for any domain where similarity among people is emphasized, such as those involving mutual support or close relationships (loosely analogous to our flood context, where all the recipients have been affected by the emergency, though not to the same extent), whereas equity or merit is preferable for economic, scientific, and technical productivity, where differences among people are paramount (analogous to the nonflood context in our study). Overall, however, as with most studies of different goods, these studies of the effect of context tend to be highly varied in both design and results, making it difficult to develop hypotheses for our study.

In order to make the effect of context more tractable, we examine two opposed contexts (nonemergency versus emergency) while holding everything else constant across contexts. Our study design therefore builds more directly on several lines of research. First is the influential study of contextual features by Kahneman, Knetsch, and Thaler (1986), which proposed a theory of fair transactions that rely on several factors including what they characterize as framing effects (see Kahneman and Tversky 1979), but which can also fruitfully be viewed as contextual effects (see Konow 2003, 1217). We likewise compare effects across opposed contexts (or "frames"). Second, several studies have also examined the effect of context in terms of scarcity, analogous to our examination of an emergency situation, as opposed to plenty. These studies have generally found that when there are sufficient or abundant resources, merit or equality predominate, but that need and efficiency gain appeal when resources are scarce (Greenberg 1981; Lane and Messe 1972; Skitka and Tetlock 1992). A similar result exists regarding allocation behavior in primarily productive versus nonproductive domains: Major, Bylsma, and Cozzarelli (1989) found that equity (or merit) was the main allocation principle used in work contexts, especially for men, in comparison to relationship contexts (see also Bierhoff, Buck, and Klein 1986; Kidder, Fagan, and Cohn 1981). 
Finally, empirical research on distributive justice, as well as analogous studies of public opinion, suggests that individual-level factors such as gender and ideology affect allocation decisions and opinions. As for gender, most studies show that women tend to be more oriented toward equality and need, whereas men tend to weigh merit more heavily (Kidder et al. 1981; Kluegel and Smith 1986; Kluegel, Mason, and Wegener 1995; Major and Deaux 1982; Michelbach et al. 2003; Scott et al. 2001). Similar gender effects have been found in analogous - and possibly relatedresearch on the application of core values to public opinion (see Chaney, Alvarez, and Nagler 1998; Gilens 1988; Kaufmann and Petrocik 1999; Shapiro and Mahajan 1986; Welch and Hibbing 1992). Nonetheless, other studies find that the more need-oriented and egalitarian tendencies of women are mediated to some degree by various factors, such as their assumptions about merit (Scott et al., 2001; see Bierhoff, Buck, and Klein 1986; Mikula 1980). Political ideology has likewise been shown to affect distributive justice behavior, with liberals more concerned with equality and conservatives with efficiency (Mitchell et al. 2003; Mitchell et al. 1993; Scott et al. 2001; Tetlock and Mitchell 1993). Similarly, conservatives tend to be less concerned with need than liberals, especially as merit level increases (see Scott et al. 2001; Skitka and Tetlock 1992, 1993; Tetlock and Mitchell 1993).

\section{Theoretical Expectations}

In conclusion, we can summarize our expectations with regard to the theoretical and empirical literature. First, our study draws on pluralist normative theories which suggest that allocation behavior should vary according to context and good. Unlike alternative theories such as utilitarianism or Rawls that offer no differential predictions, these pluralist theories suggest broad expectations about differences in behavior according to context and good. With regard to context, for example, we expect that individuals will weigh need more heavily in an emergency context (akin to Walzer's sphere of security and welfare), where recipients' need is a more salient consideration compared to a nonemergency context, where merit would be more salient (akin to Walzer's sphere of money and commodities). Pluralist theories have focused largely on spheres or allocation contexts and on the goods generally associated with those different spheres, but we can build on the intuition of these theories, as well as the theoretical framework developed in certain empirical studies, by suggesting that recipients' need for a given good depends in large part on the specificity of the relationship between the individual and the good. Thus, while all individuals need food in order to survive (suggesting an approximately equal division of such a good all else being equal), only certain individuals need a particular medicine (e.g., AZT, insulin, etc.), and therefore distribution of such goods should be largely in accordance with specific need. By contrast, while all individuals may need money in a broad sense, the fungible character of money means that there is no specific relationship between money and a given individual that makes money a particularized need, especially when other more specific needs such as food and medicine have been provided. Money is therefore less likely to be distributed according to need, all else being equal, and more likely to be distributed according to merit given the strong association between money and reward.

Second, in accordance with broadly pluralist findings of previous empirical research, we expect to find that justice behavior is structured yet complex, with individuals employing different allocation strategies in predictable ways according to various factors. More specifically, we expect allocation context and type of good to be important factors in decisions. In order to confirm and extend these previous studies of context and good, we apply the methodology of posing participants with clear tradeoffs among allocation strategies. This methodology has been employed primarily in studies of the distribution of money or income, and we also limit ourselves to tangible goods that can be readily compared. Based on previous studies, we expect that individuals will weigh merit more heavily in a nonemergency context or when distributing money in any context, whereas they will weigh need more heavily in an emergency context or when distributing prescription medicine in any context. Finally, in accordance with previous studies, we expect that individual-level attributes, such as gender and ideology, will have predictable effects on behavior.

\section{Research Design}

In order to examine how allocation context and type of good affect individuals' use of allocation principles, we employ an experimental design in which we vary the context and good and then ask participants to make decisions where these principles or allocation strategies conflict. Specifically, we analyze how individuals weigh merit, need, and equality in their allocation decisions (holding efficiency, i.e., the amount allocated 


\section{FiguRe 1 Experimental Instructions (Part 1)}

An area has experienced flooding due to heavy rains produced by a storm. There is a
relief center close to the flood area where various supplies are stored for emergency
purposes. The relief center is not in danger of being flooded. [There is a relief center where
various supplies are stored for emergency purposes. There is no emergency at this time. The
relief center needs to hire people to work. They are paid with the various supplies stored at
the center.]

You are an administrator at the relief center and must decide how these supplies should be distributed to individuals affected by the flood [working at the relief center].

Individuals from the flood area [ ] arrive at the relief center each morning. When they arrive, they fill out requests for the various supplies stored at the relief center. They can request up to 100 units of each supply (e.g., "units" of clothing). They also provide information about their income, marital and family status, health, and related information. Then they meet with a supervisor who reviews the information and approves their requests based upon their need.

During the day, these individuals unload and package the various supplies stored in warehouses at the relief center. The amount of supplies that can be distributed at the end of the day will depend in part on how much of the supplies are unloaded and packaged during the day. Therefore, these individuals are told that the amount of supplies that they unload and package may be considered when distributing the supplies.

Individuals are assigned in groups of two people to a warehouse where they work under a supervisor. They do not know their co-worker or how much their co-worker requested of any goods. Each individual works independently unloading and packaging various supplies. All of the individuals work the same amount of time. They are equally able to do the work.

At the end of each day the supplies are distributed. Several different supplies are passed out each day. You are assigned the job of distributing one of those supplies. Individuals cannot trade or sell any of the supplies after they are distributed.

The individuals come to you, the administrator, two at a time-in the pairs that worked in the same warehouse under the same supervisor. They bring:

- The approved request they filled out in the morning for the supply you are distributing. the day.

- Information about how many boxes of supplies they unloaded and packaged during

You then distribute the supply to the individuals in a way that you think is appropriate. in each case, constant). By experimentally manipulating allocation context and type of good, we can isolate the factors that influence how individuals employ these principles under different conditions.

\section{Experimental Design}

First, in order to study the effect of allocation context, each participant is randomly assigned to one of two experimental conditions: a nonemergency or an emergency condition. Figure 1 provides the first part of the experimental instructions, with the instructions for the emergency (flood) condition in italics and the nonemergency condition in brackets. We chose a flood as our example of an emergency context because it is among the more common natural disasters and because other natural disasters can themselves cause flooding (e.g., hurricanes or tsunamis). These different conditions are represented in the description of the relief center's operations in the participant instructions, where they are asked to imagine they are administrators at a relief center whose job it is to distribute various supplies. Although the task performed by the study participants is admittedly stylized, their role is analogous to that of a policy maker or bureaucrat in determining what allocation rule to employ under various conditions.

Second, in order to study the effect of different goods, participants in each allocation context condition are then randomly assigned to one of three experimental conditions representing the good they were asked to allocate: money, prescription medicine, or food. ${ }^{2}$ These two manipulations create six

\footnotetext{
${ }^{2}$ We originally included another good, cotton candy, but have dropped that experimental condition from our presentation because of the difficulty of distinguishing between "want" and "need" as an allocation principle for this particular good. Since our experimental manipulations are all between-subject, excluding this good has no effect on the results presented.
} 


\section{Figure 2 Experimental Instructions (Part 2)}

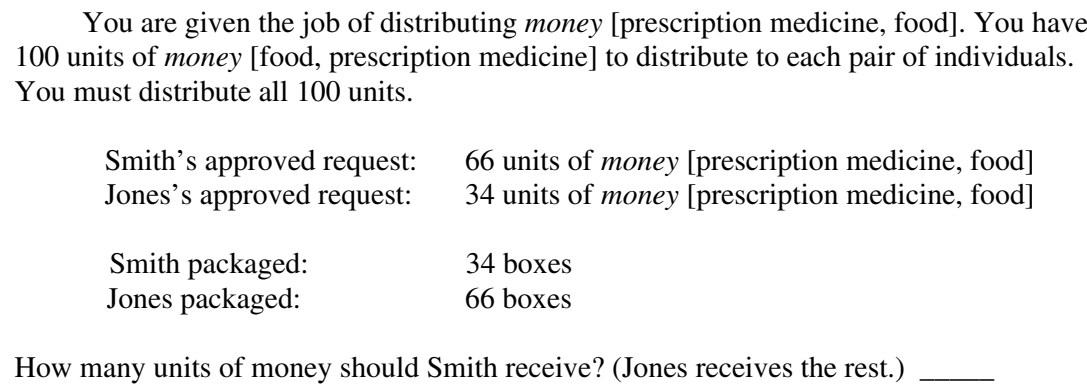

between-subject experimental conditions (context $\times$ good).

Finally, having been assigned to one of these six between-subject experimental conditions, each participant is presented with four randomly ordered allocation scenarios (within-subject). Each of these scenarios requests a separate allocation decision for a different pair of individuals (e.g., Smith and Jones) based on two pieces of information about the recipients: the amount of their approved requests for the supply being allocated and the amount of work they accomplished. Figure 2 provides these instructions.

For each scenario, we vary the amount of the recipients' approved requests (representing need) and the amount they worked (representing merit), in order to pose the participant with tradeoffs among different allocation strategies. In order to ensure that the information about the amount of work done by each recipient represents merit, we make clear that this work depends upon effort by emphasizing that the recipients worked independently, worked the same amount of time, and were equally able to do the work (for the empirical relationship between effort and merit, see Konow 2003, 1207-11). Similarly, in order to evoke the recipients' need, rather than mere want (see Braybrooke 1987), we emphasize that the recipients' requests had been approved by administrators based on income, marital and family status, health, and related information. For each of the four allocation decisions, participants distribute 100 units of the given good between a separate pair of recipients. The answers to these questions provide the data used to create the dependent variables for analysis.

In three of the four allocation scenarios, we contrast the amount of the approved request and the amount worked in order to place need and merit in opposition, thereby posing participants with opposed choices among allocation strategies. For example, participants are told that Smith had an approved request of 66 units of prescription medicine and had packaged 34 boxes of supplies, whereas Jones had an approved request of 34 units of prescription medicine and had packaged 66 boxes of supplies. In this case, then, the participant is faced with a choice as to whether to reward merit (for example, allocating 34 units to Smith and the remaining 66 units to Jones) or to reward need (for instance, giving 66 units to Smith and 34 units to Jones), or to adopt a mixed or egalitarian strategy. The three scenarios, with counterbalanced amounts for work and approved request, were: 66 vs. 34,75 vs. 25 , and 90 vs. 10 (and, in order to control for possible framing effects, the obverse equivalents: 34 vs. 66,25 vs. 75 , and 10 vs. 90). We include these three scenarios with increasingly disproportionate differences in the contributions and needs of the two recipients because, based on previous studies (Michelbach et al. 2003; Mitchell et al. 1992; Scott et al. 2001), we anticipate that participants may be increasingly more liable to reward merit where they see the recipient as particularly "deserving."

In the scenarios that contrast merit and need an answer by a participant that splits a good 50/50 between the two recipients is equivocal: it could mean that the participant is allocating according to strict equality or, alternatively, it could mean that the participant is giving equal weight to merit and need. ${ }^{3}$ In order to distinguish specifically egalitarian behavior from a mixed strategy equally balancing merit and

\footnotetext{
${ }^{3}$ Participants could in principle balance all three principlesmerit, need, and equality - but we believe that this is a rare case and, in any event, our experimental design does not allow us to calculate the weights simultaneously given to these three principles in any unambiguous manner.
} 
need, therefore, we include a fourth scenario in which the amount of work and the amount of the approved request - that is, merit and need-are not in opposition and in which allocating according to equality is therefore an unambiguously distinct strategy. So, for example, in this fourth vignette Smith had an approved request of 75 units of money and packaged 75 boxes of supplies, whereas Jones had an approved request of 25 units of money and packaged 25 boxes of supplies. In this scenario, then, an answer of 50/50 is clearly being made with an eye to equality, as opposed to reflecting a mixed strategy balancing merit and need. By comparing the response to this fourth scenario to responses in any of the other three scenarios, we can identify participants whose allocation decisions are made in accord with strict equality as opposed to a mixed strategy.

Finally, participants complete a postexperimental questionnaire requesting demographic information to be used as independent and control variables in the analyses.

\section{Experimental Setting and Participants}

Participants were 580 undergraduates, recruited for the study in political science classes at the University of California, Davis, in which they received course credit for participation. 344 participants completed the experiment in a classroom as a pen-and-paper version, and the remaining participants completed the same experiment on computers in a laboratory. Since there were no statistically significant differences between testing groups, we combined the data for all analyses. Participants were $47.1 \%$ women, and ranged in age from 18 to 49 , with a mean (and median) age of 19 years old. ${ }^{4}$

\section{Data and Analysis}

All of our analyses use a categorical variable representing participants' allocation strategies-merit, need, mixed, and egalitarian-that we create based on their responses in the allocation scenarios. While participants may allocate the good to the first

\footnotetext{
${ }^{4} \mathrm{We}$ are reasonably confident that there is nothing specific about our respondent sample that should raise undue concerns about the generalizability of our results. We pretested our experiment at two other universities (the University of Houston and Louisiana State University) using students recruited in both political science and psychology courses. Furthermore, the student population at the University of Houston is considerably more demographically varied in terms of age, race or ethnicity, and SES than a typical undergraduate population (see Scott et al. 2001, 762). We found very similar results in our pretests using these different populations as we did in our final study.
}

recipient in the pair anywhere within the range of 0-100 units (with the remainder going to the second recipient), our theory suggests that their allocation decisions will be based on the several distinct allocation principles. Participants' decisions should, therefore, cluster on the responses representing one of these principles or a clear tradeoff between them, enabling us to categorize their behavior with confidence. As noted above, since participants' behavior was consistent across the different allocation scenarios, we will present only the categorization of their behavior based on the 66 vs. 34 scenario (using the fourth, noncontrasted scenario to identify egalitarians).

Analysis of the data confirms that the clear majority of participants do indeed cluster their responses as anticipated. Indeed, about half of the participants are readily classified, since their responses indicate an unambiguous reliance upon either merit or need, with $28 \%$ of participants across experimental conditions allocating strictly according to need and $21 \%$ strictly according to merit. Another $25 \%$ of participants chose an even 50/50 split. A total of $74 \%$ of participants therefore chose one of the focal point responses, exhibiting well-behaved preferences.

In order to identify egalitarian behavior and to distinguish it from a mixed strategy balancing merit and need among those choosing a 50/50 split, we compared participants' behavior in the 66 vs. 34 scenario (on which we shall focus in presenting our results) where merit and need are contrasted to their response in the fourth scenario, where an egalitarian response is unambiguous. In this fourth scenario, $12.5 \%$ of participants chose the response of a 50/50 split between recipients, indicating strictly egalitarian behavior. Of these, $76.0 \%$ also chose an even split in the 66 vs. 34 scenario, meaning that we can confidently identify $9.5 \%$ of participants overall in the 66 vs. 34 scenario as egalitarians since they exhibit strictly egalitarian behavior in both scenarios. All of the other participants who chose an even 50/50 split are therefore classified as adopting a mixed strategy. Finally, we classified the relatively few remaining participants whose answers did not cluster on one of these focal point answers by simply assigning them to the category (merit, mixed, or need) to which they were arithmetically closest.

In all of our statistical analyses we employ a multinomial logit regression using a dependent variable with four categories representing the four allocation strategies used by participants: merit, need, equality, and mixed. In order to analyze allocation context and good, in the full model we include 
separate variables for each of the six experimental conditions to which a participant can be assigned (context $\times$ good). We further include independent variables for Gender (with Woman=1), Ideology (coded 0-6, with 0 being extremely liberal), and a control variable for Mother's Education as a proxy for SES (coded 0-6, with 0 being less than high school education). Finally, we include a variable to control for possible framing effects in the presentation of the scenario, Merit Frame. ${ }^{5}$

\section{Results}

We are interested in examining differences in allocation strategies across context and good as well as in determining the individual-level factors such as gender and ideology that affect participants' choice of strategy. When analyzing the results of the behavior in the different allocation scenarios that contrast merit and need (66 vs. 34,75 vs. 25 , and 90 vs. 10 ), we found nearly identical behavior by participants across scenarios. We will therefore henceforth focus on the results based on the 66 vs. 34 scenario. $^{6}$

Table 1 reports the results of two multinomial logit regression models that analyze allocation strategies based on the 66 vs. 34 allocation scenario. In the first, reduced model (Column A), we analyze only the allocation context (nonflood vs. flood) for an initial test of the effect of allocation context alone, and in the full model (Column B) we analyze the experimental manipulations of both context and good. The merit category serves as the baseline for these analyses, and, since we expect that the NonfloodMoney condition will be the most extreme in terms of merit behavior, we omit that condition in the full

\footnotetext{
${ }^{5}$ The Merit Frame variable is coded 1 if the first recipient in an allocation decision had the higher amount worked in comparison to the second recipient (e.g., 66 vs. 34) and 0 if the first recipient had the lower amount worked (e.g., 34 vs. 66). In addition, in order to test for framing effects due to the order in which the four vignettes were presented to the participant we included a variable for order of presentation in initial analyses, but do not include it in the final models since it was not statistically significant and since omitting it did not change any other results.
}

${ }^{6} \mathrm{We}$ did find that there was a very slight increase in the likelihood of merit behavior in the 90 vs. 10 scenario, as expected, increasing the predicted probability of a participant allocating a given good by about $5 \%$ in comparison to the other two scenarios, and generally at the reduced probability of allocating according to a mixed strategy. The only notable exception to the difference in merit behavior for participants in the 90 vs. 10 scenario was the allocation of prescription medicine in the flood condition, with a predicted probability of $30.4 \%$ in comparison to $16.7 \%$ in the 66 vs. 34 scenario. model so that it provides the comparison group for the behavior in the other conditions.

The reduced model (Column A) reveals that context affects participants' choice of allocation strategy as expected. The positive and significant coefficient for the Flood variable for both the need and mixed categories indicates that participants in the flood condition were more likely across goods to allocate according to a mixed strategy or according to need than those in the nonflood context. Conversely, if we change the baseline category for the analysis we can also see that participants were less likely to allocate according to merit in the flood as opposed to the nonflood context, also as expected. Finally, participants were equally likely to allocate according to equality in both contexts.

If the reduced model demonstrates that participants' allocation behavior across goods changes according to context, the full model, analyzing the effect of both context and good (Column B), shows that participants' allocation strategies vary according to good as well. Although we will detail these results below, we can see that participants are more likely to allocate money according to merit and medicine according to need, regardless of context, and are somewhat more likely to allocate food according to equality across contexts, at least in comparison to when allocating the other goods. Finally, with regard to individual-level variables, we find a somewhat surprising effect with regard to gender. Namely, we find that women's and men's choice of allocation strategies is indistinguishable, which is somewhat contrary to our expectation, based on previous research, that women are more likely to allocate according to need and men are more likely to rely on merit. The results for ideology are, however, in line with our expectations, with liberals being somewhat more likely to allocate according to need (as well as according to a mixed strategy) in comparison to according to merit and vice versa for conservatives. ${ }^{7}$ Since men and women behave similarly across different allocation contexts and goods, we will henceforth combine them in presenting our results.

\footnotetext{
${ }^{7}$ As for the control variable for the Merit Frame, we do detect a statistically significant effect in one instance. Namely, those participants who were presented with the higher amount worked for the first recipient (i.e., those with the Merit Frame coded 1) were somewhat more likely to allocate according to need as opposed to merit. Since this framing effect was not consistently statistically significant either in our analysis of the 66 vs. 34 allocation scenario or across the other allocation scenarios, and since its effects were quite modest, we simply control for its effects.
} 
Table 1 Multinomial Logit Regression Analysis of Allocation Behavior

\begin{tabular}{|c|c|c|c|c|c|c|}
\hline \multirow{2}{*}{$\begin{array}{l}\text { Baseline Comparison } \\
\text { Category: Merit }\end{array}$} & \multicolumn{2}{|c|}{ Need } & \multicolumn{2}{|c|}{ Equality } & \multicolumn{2}{|c|}{ Mixed } \\
\hline & A & B & A & B & A & B \\
\hline Flood & $\begin{array}{l}.82^{\star} \\
(.23)\end{array}$ & & $\begin{array}{l}.40 \\
(.33)\end{array}$ & & $\begin{array}{l}.56^{*} \\
(.24)\end{array}$ & \\
\hline Nonflood-Medicine & - & $\begin{array}{l}.72^{*} \\
(.35)\end{array}$ & - & $\begin{array}{l}.42 \\
(.64)\end{array}$ & - & $\begin{array}{l}1.03^{\star} \\
(.39)\end{array}$ \\
\hline Nonflood-Food & - & $\begin{array}{l}.24 \\
(.34)\end{array}$ & - & $\begin{array}{l}1.02^{\star} \\
(.51)\end{array}$ & - & $\begin{array}{l}.82^{*} \\
(.37)\end{array}$ \\
\hline Flood-Money & - & $\begin{array}{l}.68 \\
(.39)\end{array}$ & - & $\begin{array}{l}.68 \\
(.39)\end{array}$ & - & $\begin{array}{l}1.06^{*} \\
(.40)\end{array}$ \\
\hline Flood-Medicine & - & $\begin{array}{l}1.67^{\star} \\
(.41)\end{array}$ & - & $\begin{array}{l}1.12 \\
(.68)\end{array}$ & - & $\begin{array}{l}1.65^{\star} \\
(.45)\end{array}$ \\
\hline Flood-Food & - & $\begin{array}{l}.73^{*} \\
(.37)\end{array}$ & - & $\begin{array}{l}1.30^{*} \\
(.56)\end{array}$ & - & $\begin{array}{l}.79 \\
(.42)\end{array}$ \\
\hline Gender & $\begin{array}{l}-.17 \\
(.23)\end{array}$ & $\begin{array}{l}-.17 \\
(.23)\end{array}$ & $\begin{array}{l}-.15 \\
(.32)\end{array}$ & $\begin{array}{l}-.17 \\
(.32)\end{array}$ & $\begin{array}{l}-.17 \\
(.24)\end{array}$ & $\begin{array}{l}-.19 \\
(.24)\end{array}$ \\
\hline Ideology & $\begin{array}{r}-.17^{\star} \\
(.07)\end{array}$ & $\begin{array}{r}-.17^{\star} \\
(.08)\end{array}$ & $\begin{array}{l}-.16 \\
(.10)\end{array}$ & $\begin{array}{l}-.16 \\
(.10)\end{array}$ & $\begin{array}{r}-.18^{\star} \\
(.08)\end{array}$ & $\begin{array}{r}-.18^{\star} \\
(.08)\end{array}$ \\
\hline Mother's Education & $\begin{array}{l}.08 \\
(.07)\end{array}$ & $\begin{array}{l}.07 \\
(.07)\end{array}$ & $\begin{array}{r}-.07 \\
(.10)\end{array}$ & $\begin{array}{l}-.07 \\
(.10)\end{array}$ & $\begin{array}{l}.05 \\
(.07)\end{array}$ & $\begin{array}{l}.05 \\
(.07)\end{array}$ \\
\hline Merit Frame & $\begin{array}{l}1.18^{*} \\
(.23)\end{array}$ & $\begin{array}{l}1.41^{*} \\
(.25)\end{array}$ & $\begin{array}{l}.43 \\
(.35)\end{array}$ & $\begin{array}{l}.62 \\
(.38)\end{array}$ & $\begin{array}{l}.22 \\
(.26)\end{array}$ & $\begin{array}{l}.47 \\
(.27)\end{array}$ \\
\hline Constant & $\begin{array}{l}-.50 \\
(.41)\end{array}$ & $\begin{array}{c}-.73 \\
(.43)\end{array}$ & $\begin{array}{c}-.71 \\
(.50)\end{array}$ & $\begin{array}{r}-1.28^{*} \\
(.62)\end{array}$ & $\begin{array}{c}-.13 \\
(.43)\end{array}$ & $\begin{array}{l}-.70 \\
(.49)\end{array}$ \\
\hline $\begin{array}{l}\mathrm{N} \\
\mathrm{Chi}^{2}, \mathrm{df}, \mathrm{p}\end{array}$ & & & $\begin{array}{l}\text { ed Mode } \\
\text { Model }\end{array}$ & $\begin{array}{l}\text { A): } 57 \\
\text { B): } 78.2 \text {, }\end{array}$ & & \\
\hline
\end{tabular}

Note: ${ }^{\star} p<.05$, two-tailed test with standard errors in parentheses.

In order to make these results easier to interpret substantively, we calculated predicted probabilities for the full model of the multinomial logit regression. ${ }^{8}$ The graphical presentation of the predicted probabilities (Figure 3) enables us to make several comparisons following from our hypotheses and also to summarize our findings before going through them in more detail.

- First, we can compare participants' allocation strategies within any specific experimental condition (context $\times$ good). For example, in the NonfloodMoney condition we see that a predicted $46.1 \%$ of participants allocated according to merit, $27.5 \%$ according to need, $8.7 \%$ according to strict equality, and $17.7 \%$ according to a mixed strategy. Looking across all of the separate conditions, then,

${ }^{8}$ More specifically, in order to generate predicted probabilities for each experimental condition, we set the independent variables (Ideology, Mother's Education, and the Merit Frame) at their means, and, since we found no statistically significant difference in the behavior of men and women, set Gender at 0 . we can see that participants definitely employ a variety of allocation strategies.

- Second, we can compare strategies in allocating a specific good across allocation context, for example, the allocation of money in the nonflood versus flood conditions. Comparing the allocation of each good across context, then, we see that context affects the choice of strategy for at least two of the goods, money and prescription medicine, with participants far more likely to emphasize merit for both goods in the nonflood condition and more likely to emphasize need for both goods in the flood context, as expected.

- Third, we can compare allocation strategies across goods within an allocation context, for example the allocation of money compared to prescription medicine within the flood condition. We see, then, that participants across allocation contexts emphasize merit when allocating money and need when allocating prescription medicine, both as expected. When allocating food, in turn, participants adopt a more diverse set of allocation strategies, notably 


\section{Figure 3 Predicted Probabilities for Allocation Behavior}

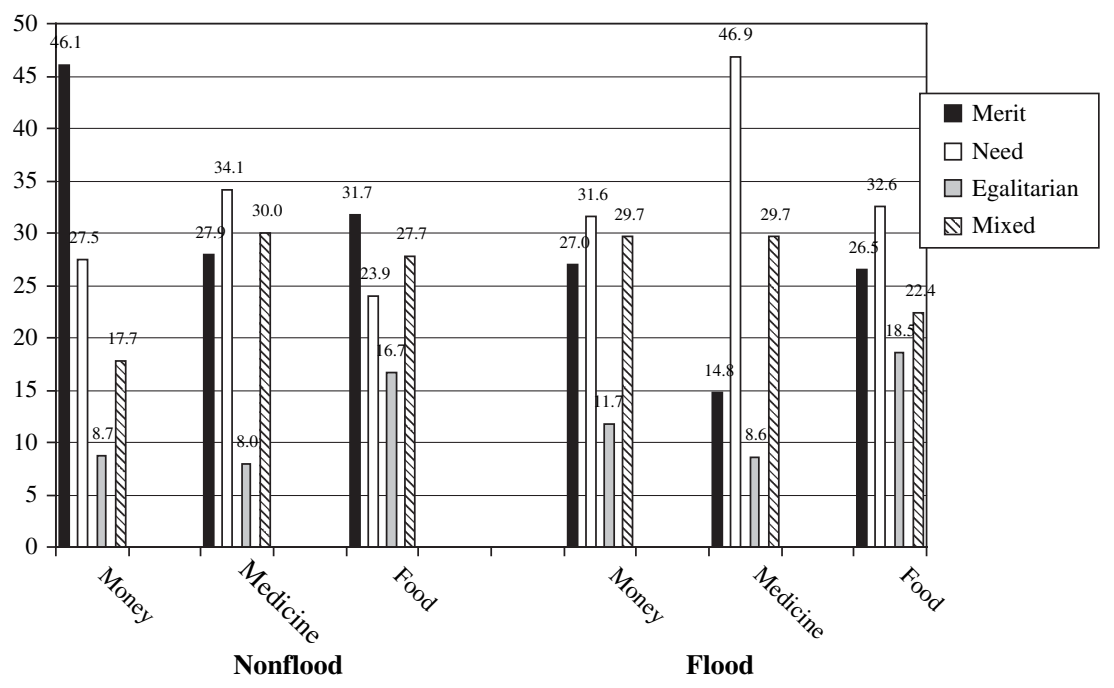

emphasizing equality across allocation contexts somewhat more in comparison to when they allocate the other goods.

For simplicity's sake, we will concentrate on the results for the two main and opposed allocation strategies-merit and need-and then discuss the results concerning egalitarian behavior.

Our first hypothesis concerns the effect of context (nonflood vs. flood) on allocation behavior. Although the initial analysis of the effect of context alone in the reduced model showed an overall effect, when we look at differences in allocation strategy for each of the different goods in the full model we see that the allocation context has a statistically significant effect for money and prescription medicine, but not for food. In other words, the overall increased propensity for participants to allocate according to merit in the nonflood context is driven by their allocation of prescription medicine and particularly of money. Likewise, the overall increased likelihood that participants would allocate according to need in the flood context was due to their behavior with regard to money and especially to prescription medicine.

The effect of allocation context on the distribution of both money and prescription medicine is quite striking. Our expectations were that participants overall would be most oriented toward merit when allocating money in the nonflood condition, and the results confirm this hypothesis. In fact, participants in the Nonflood-Money condition were by far most likely to allocate according to merit (with a predicted probability of $46.1 \%$ ) in comparison to any other experimental condition, including the Flood-Money condition (27.0\%). We also see a significant change across allocation contexts in the probability of a participant distributing money according either to a mixed strategy or to need, with the probability of allocating money according to need rising from $27.5 \%$ in the nonflood context to $31.6 \%$ in the flood context. (The change in the probability of a participant allocating according to a mixed strategy is almost identical in direction and magnitude.) All of these effects are statistically significant differences $(\mathrm{p}<.05)$.

The results are similarly striking with regard to prescription medicine, where we expected that participants overall would favor need as an allocation principle. Participants in the Flood-Medicine condition were by far more likely to allocate according to need $(46.9 \%)$ than those in any other group, including the Nonflood-Medicine condition (34.1\%). Likewise, as with the allocation of money, the probability that a participant allocating prescription medicine will do so according to merit drops nearly in half from the nonflood context $(27.9 \%)$ to the flood context $(14.8 \%)$. Finally, in contrast to money and prescription medicine, the allocation strategies used for distributing food were not statistically significantly influenced by context.

We have focused thus far on merit and need, but we find one notable result with regard to equality as an allocation strategy. Namely, while the predicted probability of allocating according to equality generally varies with a relatively small but consistent range of about $10 \%$ of participants across conditions, there were significantly more egalitarians with regard 
to one good: food. Specifically, the predicted probability of a participant allocating food in the flood condition according to equality is $18.5 \%$, which is a considerably higher likelihood than in any other condition, except for in the Nonflood-Food condition, where we see a predicted $16.7 \%$. The increased probability of allocating according to equality more for food than for the other goods is, however, only a marginally significant effect. ${ }^{9}$

In sum, then, we have found that both allocation context and good matter for determining what allocation strategies participants are likely to adopt. As for allocation context, we have seen that participants emphasize merit in the nonflood context and need in the flood context. As for goods, we have found that across allocation contexts participants are most likely to allocate money according to merit, prescription medicine according to need, and that they are somewhat more likely to show egalitarian behavior when distributing food than any other good.

\section{Discussion}

We have examined the effects of allocation context and type of good on allocation decisions in order to further our understanding of the structure of distributive justice behavior. We have examined the distribution of goods central to social welfare programsmoney, prescription medicine, and food-and different allocation contexts in order to understand how individuals think about the distribution of goods both in the fair weather of the mundane distributive policies of the modern state as well as in the foul weather of natural disasters that bring the issues of distributive justice to the fore. The allocation task performed by our participants is admittedly stylized, and very few individuals are likely to find themselves acting as supervisors in a relief center with complete knowledge of the relevant attributes of the context, goods, and recipients. Our goal, however, is to understand the structure of allocation behavior, and especially how individuals weigh competing allocation principles and what factors affect how they use these principles. With a better understanding of justice behavior under these idealized conditions, we can then see how this behavior is refracted through the prism of interested behavior

\footnotetext{
${ }^{9}$ The increased egalitarian behavior regarding food is statistically significant only when comparing between food in the flood condition and money in the nonflood condition $(\mathrm{p}<.05)$ and between food in the nonflood condition and money in the nonflood condition $(\mathrm{p}<.10)$.
}

and other factors at play in making distributive decisions. Our hope is that the results of our study and similar ones can be extended to actual behavior by politicians, policy makers, and citizens when determining who gets what, when, and how.

Our results suggest that individuals' distributive justice behavior is strongly influenced by both allocation context and type of good or, more specifically, we have shown that the distribution of different types of goods depends critically on context (i.e., the two variables interact). We expected that individuals would emphasize different allocation principles according to the context. Overall, this expectation was confirmed, and we saw that participants tended to allocate more according to merit in the nonflood context and to be more oriented toward need in the flood context. We also expected that individuals would emphasize different principles according to the type of good being distributed, and once again we found overall that this was the case. Notably, individuals tended to emphasize merit when allocating money and need when allocating prescription medicine.

Our results concerning the two main and opposed allocation principles of merit and need are thus generally in accord with our expectations and are in keeping with studies that have examined allocation context or good, including Skitka's (1999) similar study. The most striking comparison in this regard would be the behavior of participants in the NonfloodMoney condition compared to the Flood-Medicine condition, where the proportion of participants allocating according to merit $(46.1 \%)$ in the NonfloodMoney condition is almost exactly the same proportion of participants allocating according to need (46.9\%) in the Flood-Medicine condition. Despite the intuitively plausible if striking character of these results, we also see nonobvious findings. Perhaps most remarkably, even though participants in the FloodMedicine condition tend as expected to emphasize need, fully $14.8 \%$ of respondents in that condition still chose to allocate according to merit. In other words, faced with the dilemma in an emergency context of distributing prescription medicine between Smith and Jones, where Smith had a demonstrated need of 66 units of prescription medicine and packaged 34 boxes of supplies whereas Jones needed only 34 units of prescription medicine and packaged 66 boxes, a sizeable proportion of individuals chose to give Smith only 34 units of medicine and reward Jones with 67 units. In other words, we found that respondents do not behave in a lockstep fashion according to context and good, and that they still 
employ a surprising variety of allocation strategies in every condition

Turning to our third good, food, and our third major allocation principle, equality, we found a somewhat unexpected and intriguing result. Compared to money and prescription medicine, participants employed the widest variety of allocation strategies when allocating food and, more interestingly, exhibited the most attention to equality. This result might be due to some participants having reasoned that all recipients have a general need for food whereas they have differential specific needs for prescription medicine. If so, then this finding would further increase doubts raised by some researchers (see Konow 2003, 1232-34) as to whether equality is indeed a separate allocation principle, or instead is either too closely related to need to be distinguishable or serves as a heuristic in the absence of relevant information. Clearly, further research is necessary to understand how-or whether-equality is a distinct allocation principle.

We were also interested in the effect of individual-level determinants of allocation behavior, especially gender and ideology. Based upon previous research into distributive justice and public opinion we expected that women (and liberals) would be more oriented on average toward need and, conversely, that men (and conservatives) would tend to emphasize merit. While we found the expected result for ideology, we did not see any gender difference in allocation behavior. The absence of an overall gender difference in our study is somewhat surprising. One potential explanation for this result is that our experiment is a microlevel study where participants do not have to make assumptions or to extrapolate information about recipients or context, as opposed to most macrolevel studies, or public opinion surveys, concerning views about the hypothetical or actual distribution of income or other goods across an entire society. In our study, participants in principle perfectly know all the relevant the characteristics of the allocation context, good, and recipients because we stipulate these factors as part of the experimental manipulations themselves. Most importantly, we stipulate the main characteristics of the recipients: their demonstrated need for a given good and their contribution to the (same) productive task. Women and men participants in our study may therefore behave in the same way because they share the same information and assumptions. Other research has shown that in the absence of specific information participants tend to extrapolate or to make assumptions in making decisions or judgments (see Kahneman, Knetsch, and Thaler 1986). What the absence in our study of a difference of behavior between women and men may suggest, then, is that the observed gender differences in other studies regarding distributive justice behavior or core values determining public opinion could be due in large measure to the different assumptions women and men make concerning the overall distribution of goods in a society. Women and men may, for example, tend to make different assumptions about the characteristics of the recipients of social welfare programs: for instance, whether the economically disadvantaged are "deservingly" poor or not. If this conjecture is correct, the implication is that differences in the core beliefs and values of women and men are not the principal underlying cause for observed gender differences, but that assumptions concerning the features of the distributive context, as they interact with these core values, explain the observed gender gap in distributive justice behavior and support for social welfare policies. Our study thus suggests some obvious lines of research that would confirm or disconfirm this hypothesis about gender.

\section{Conclusion}

If the modern state is concerned essentially with who gets what, when, and how, then questions about the effect of context and type of good on the distribution of resources - and their fair distribution-are central to politics and public opinion. These issues of distributive justice were dramatically raised by the allocation of goods in the wake of the flooding caused by the hurricanes Katrina and Rita, but they are of perennial concern to politicians and policy makers in designing and implementing social welfare and other government programs concerning a variety of different goods, especially in times of emergency or scarcity. Our study makes both a theoretical and an empirical contribution to our understanding of allocation behavior and distributive justice with implications for understanding the distributive decisions of policy makers as well as citizens' views of the fairness and legitimacy of policies.

\section{Acknowledgments}

We would like to thank for their comments and suggestions: James Fowler, Paul David Hewson, Cindy Kam, James Konow, Richard Matland, Jim Spriggs, and Elizabeth Zechmeister. 
Manuscript submitted 10 April 2007

Manuscript accepted for publication 16 November 2008

\section{References}

Bierhoff, Hans W., Ernst Buck, and Renate Klein. 1986. "Social Context and Perceived Justice." In Justice in Social Relations, ed. Hans W. Bierhoff, Ronald L. Cohen, and Jerald Greenberg. New York: Plenum, 165-85.

Brams, Steven J., and Alan D. Taylor. 1996. Fair Division: From Cake-cutting to Dispute Resolution. Cambridge: Cambridge University Press.

Braybrooke, David. 1987. Meeting Needs. Princeton, NJ: Princeton University Press.

Chaney, Carole Kennedy, R. Michael Alvarez, and Jonathan Nagler. 1998. "Explaining the Gender Gap in U.S. Presidential Elections, 1980-1992.” Political Research Quarterly 51 (June): 311-39.

Deutsch, Morton. 1986. "Cooperation, Conflict, and Justice." In Justice in Social Relations, eds. Hans W. Bierhoff, Ronald L. Cohen, and Jerald Greenberg. New York: Plenum, 3-18.

Elster, Jon. 1992. Local Justice. New York: Sage.

Elster, Jon. 1993. "Justice and the Allocation of Scarce Resources." In Psychological Perspectives on Justice: Theory and Applications, eds. Barbara A. Mellers and Jonathan Baron. Cambridge: Cambridge University Press, 259-78.

Fehr, Ernst, and Klaus M. Schmidt. 1999. "A Theory of Fairness, Competition, and Cooperation." Quarterly Journal of Economics 114 (3): 817-68.

Feldman, Stanley. 1988. "Structure and Consistency in Public Opinion: The Role of Core Beliefs and Values." American Journal of Political Science 32 (2): 416-40.

Foa, Uriel G., and Edna B. Foa. 1974. Societal Structures of the Mind. Springfield, IL: Charles C. Thomas.

Frohlich, Norman, and Joe A. Oppenheimer. 1992. Choosing Justice: An Experimental Approach to Ethical Theory. Berkeley: University of California Press.

Frohlich, Norman, Joe Oppenheimer, and Anja Kurki. 2004. "Modeling Other-Regarding Behavior and An Experimental Test." Public Choice 119: 91-117.

Gilens, Martin. 1988. "Gender and Support for Reagan: A Comprehensive Model of Presidential Approval." American Journal of Political Science 32: 19-49.

Greenberg, Jerald. 1981. "The Justice of Distributing Scarce and Abundant Resources." In The Justice Motive in Social Behavior, eds. Melvin J. Lerner and S. C. Lerner. New York: Plenum, 289-316.

Hegtvedt, Karen A., and Karen S. Cook. 1999. "Distributive Justice: Recent Theoretical Developments and Applications." In The Justice Reader, eds. Joseph Sanders and V. Lee Hamilton. New York: Plenum, 93-132.

Herlocker, Caryn E., Scott T. Allison, John D. Foubert, and James K. Beggan. 1997. "Intended and Unintended Overconsumption of Physical, Spatial, and Temporal Resources." Journal of Personality and Social Psychology 73: 992-1004.

Kahneman, Daniel, Jack L. Knetsch, and Richard Thaler. 1986. "Fairness as a Constraint on Profit Seeking: Entitlements in the Market." American Economic Review 76: 728-41.

Kahneman, Daniel, and Amos Tversky. 1979. "Prospect Theory: An Analysis of Decision Under Risk." Econometrica 47 (2): 277-78.
Kaufman, Karen M., and John R. Petrocik. 1999. "The Changing Politics of American Men: Understanding the Sources of the Gender Gap." American Journal of Political Science 43 (July): 864-87.

Kidder, Louise H., Michele A. Fagan, and Ellen S. Cohn. 1981. "Giving and Receiving: Social Justice in Close Relationships." In The Justice Motive in Social Behavior, eds. Melvin J. Lerner and S. C. Lerner. New York: Plenum, 261-84.

Kluegel, James R., and Eliot Smith. 1986. Beliefs about Equality: Americans' Views of What is and What Ought to Be. New York: Aldine.

Kluegel, James R., David S. Mason, and Bernd Wegener. 1995. Social Justice and Political Change. New York: Aldine.

Konow, James. 2001. "Fair and Square: The Four Sides of Distributive Justice." Journal of Economic Behavior and Organization 46 (2): 137-64.

Konow, James. 2003. "Which Is the Fairest One of All? A Positive Analysis of Justice Theories." Journal of Economic Literature 41 (December): 1188-1239.

Lane, Irving M., and Lawrence A. Messé. 1972. "Distribution of Insufficient, Sufficient, and Oversufficient Rewards: A Clarification of Equity Theory." Journal of Personality and Social Psychology 21: 228-33.

Lerner, Melvin J., and Sally C. Lerner. 1981. The Justice Motive in Social Behavior: Adapting to Times of Scarcity and Change. New York: Plenum.

Leventhal, Gerald S., Jurgis Karuza, Jr., and William R. Fry. 1980 "Beyond Fairness: A Theory of Allocation Preferences." In Justice and Social Interaction, ed. Gerold Mikula. New York: Springer-Verlag, 167-218.

Major, Brenda, Wayne H. Bylsma, and Catherine Cozzarelli. 1989. "Gender Differences in Distributive Justice Preferences: The Impact of Domain." Sex Roles 21 (7/8): 487-97.

Major, Brenda, and Kay Deaux. 1982. "Individual Differences in Justice Behavior." In Equity and Justice in Social Behavior, eds. L. Berkowitz and G. W. Walster. New York: Academic Press, $43-76$.

Michelbach, Philip A., John T. Scott, Richard E. Matland, and Brian H. Bornstein. 2003. "Doing Rawls Justice: An Experimental Study of Distributive Justice Norms." American Journal of Political Science 47 (2): 523-39.

Mikula, Gerold. 1980. "On the Role of Justice in Allocation Decisions." In Justice and Social Interaction, ed. Gerold Mikula. New York: Springer-Verlag, 127-66.

Miller, David. 1999. Principles of Social Justice. Cambridge: Harvard University Press.

Mitchell, George, Philip E. Tetlock, Barbara A. Mellers, and Lisa Ordóñez. 1993. "Judgments of Social Justice: Compromises between Equality and Efficiency." Journal of Personality and Social Psychology 65: 629-39.

Mitchell, George, Philip E. Tetlock, Daniel G. Newman, and Jennifer S. Lerner. 2003. "Experiments behind the Veil: Structural Influences on Judgments of Social Justice." Political Psychology 24 (3): 519-47.

Rawls, John. 1971. A Theory of Justice. Cambridge: Harvard University Press.

Schwinger, Thomas. 1980. "Just Allocations of Goods: Decisions among Three Principles." In Justice and Social Interaction, ed. Gerold Mikula. New York: Springer-Verlag, 95-125.

Scott, John T., Richard E. Matland, Philip A. Michelbach, and Brian H. Bornstein. 2001. "Just Deserts: An Experimental Approach to Distributive Justice," American Journal of Political Science 45 (3): 749-67. 
Shapiro, Robert Y., and Harpreet Mahajan. 1986. "Gender Differences in Policy Preferences: A Summary of Trends from the 1960s to the 1980s." Political Opinion Quarterly 50: 42-61.

Skitka, Linda J. 1999. "Ideological and Attributional Boundaries on Public Compassion: Reactions to Individuals and Communities Affected by a Natural Disaster." Personality and Social Psychology Bulletin 25 (7): 793-808.

Skitka, Linda J., and Philip E. Tetlock. 1992. "Allocating Scarce Resources: A Contingency Model of Distributive Justice." Journal of Experimental Social Psychology 28: 1205-23.

Skitka, Linda J., and Philip E. Tetlock. 1993. "Of Ants and Grasshoppers: The Political Psychology of Allocating Public Assistance." In Psychological Perspectives on Justice: Theory and Applications, eds. Barbara Mellers and Jonathan Baron. Cambridge: Cambridge University Press, 205-33.

Tetlock, Philip E., and Gregory Mitchell. 1993. "Liberal and Conservative Approaches to Justice: Conflicting Psychological Portraits." In Psychological Perspectives on Justice: Theory and Applications, eds. Barbara Mellers and Jonathan Baron. Cambridge: Cambridge University Press, 234-55.
Törnblom, Kjell Y. 1992. "The Social Psychology of Distributive Justice." In Justice: Interdisciplinary Perspectives, ed. Klaus R. Scherer. Cambridge: Cambridge University Press, 177-236.

Törnblom, Kjell Y., and Uriel G. Foa. 1983. "Choice of a Distribution Principle: Crosscultural Evidence on the Effects of Resources." Acta Sociologica 2: 161-73.

Tyler, Tom R., Robert J. Boeckmann, Heather J. Smith, and Yuen J. Huo. Social Justice in a Diverse Society. 1997. Boulder, CO: Westview.

Walzer, Michael. 1983. Spheres of Justice: A Defense of Pluralism and Equality. New York: Basic Books.

Welch, Susan, and John Hibbing. 1992. "Financial Conditions, Gender, and Voting in American National Elections." Journal of Politics 54 (February): 197-213.

John T. Scott is professor of political science, University of California, Davis, Davis, CA 95616.

Brian H. Bornstein is professor of psychology, University of Nebraska, Lincoln, Lincoln, NE 68588. 